\section{Tide turns against LD50}

\section{London}

THE end may be near for the LD50 test, the controversial procedure used widely to assess the toxicity of new chemicals, which necessitates the death of large numbers of experimental animals. The Paris-based Organization for Economic Cooperation and Development (OECD) is expected to adopt new guidelines for toxicity testing next month that would replace the LD50 test with a new procedure that looks for the toxic effects of a fixed, but sub-lethal, dose of a chemical on a small group of animals. The OECD guidelines are the leading international standard for toxicity testing, and any changes to them are important because all the developed nations that make up OECD's membership demand stringent tests of a new chemical's toxicity before it can be marketed.

The purpose of the LD50 test is to identify the dose of a chemical that kills 50 per cent of a group of animals. But because that necessarily implies the killing of a large number of the animals (usually rats), the test has long been opposed by animal welfare groups. The first LD50 tests, in the late 1920 s, often involved 100 animals each, but it is now more usual to use some 30 animals per test. Nevertheless, Phil Botham, from ICI's Central Toxicology Laboratory in Cheshire, says toxicologists have also become unhappy with the test, and over the past decade have been searching for a less crude alternative.

The impetus for the present moves within OECD comes largely from the British Toxicology Society. In the early 1980 s, the society developed a 'fixed dose' procedure, which requires fewer animals to test a new chemical and measures subtle toxicological effects, rather than a straightforward distinction between life and death.

OECD decided to review its guidelines after the publication last year of a trial involving many of the leading toxicology laboratories in Europe, the United States and Japan, which endorsed the fixed-dose method. OECD settled on a test in which ten rats (five of each sex) are given a single dose of either $5,50,500$ or $2000 \mathrm{mg}$ per $\mathrm{kg}$ of the chemical being tested. Botham, who has been advising OECD on the new guidelines, says that an experienced toxicologist can often predict, given some basic knowledge about the chemical being tested, which dose will show some toxic effects without killing many of the rats involved. If the initial dose chosen is too high or too low, a second test with ten rats is run, at a different dose. In practice, testing a new chemical using the fixed-dose method requires an average of 17 rats, says Botham, and deaths by poisoning should be relatively rare - a substantial improvement on the wasteful LD50.

Nevertheless, OECD's attempt to do

\section{SPECIES REINTRODUCTION}

away with the LD50 test ran into a brick wall at a meeting in Paris in May, when officials from the United States and Japan unexpectedly announced that they could not accept the specific fixed-dose proposals being put forward by OECD. The problem, says Richard Hill, from the US Environmental Protection Agency (EPA), was that the doses chosen by OECD fit well with European classifications for whether a chemical is 'very toxic', 'toxic' or 'harmful', but less well with the US or Japanese systems. EPA classifies chemicals similarly, but the divisions between the different categories are set at different doses. EPA also was reluctant to adopt a test that gave no direct measurement of the minimum lethal dose for a substance.

But these differences now seem to have been ironed out, after a meeting in Washington late last month. As a compromise, OECD's chemicals division has agreed to recommend that a preliminary 'sighting study' be carried out before each fixed- dose test. The idea is to test single rats (probably females, which are generally more sensitive to poisoning) with varying doses of the chemical, until a dose is found that will just kill. This would allow US toxicologists to collect some data on the minimum lethal dose of a chemical, albeit of dubious statistical relevance.

The sighting study may also allow the Americans and Japanese to test toxicity at doses other than the four standards chosen for the main fixed-dose trials - which would help in applying the fixed-dose data to the US and Japanese systems for classifying dangerous chemicals.

The OECD's policy-making council is due to consider the changes at a meeting in Paris on 24 November, and Hugo van Looy, from OECD's chemicals division, says "the prospects are good" for the new recommendations to be accepted. Once the OECD changes its guidelines on toxicity testing, the European Commission, which has been considering a similar change for some time (Nature 341, 680; 1989 ) is expected to rapidly follow suit.

Peter Aldhous

\title{
New twist in snail saga
}

Predatory snails still stalk the tiny South Pacific island of Moorea three decades after a well-intentioned effort at biological control went disastrously wrong, researchers returning from a expedition to the island said last week. But the appetite of the rampaging human-introduced Euglandina snails for snails of other species on the island may soon be their undoing. In less than a decade, says expedition member Roger Klocek of Chicago's John Shedd Aquarium, "they will have eaten their way through all the other snails on

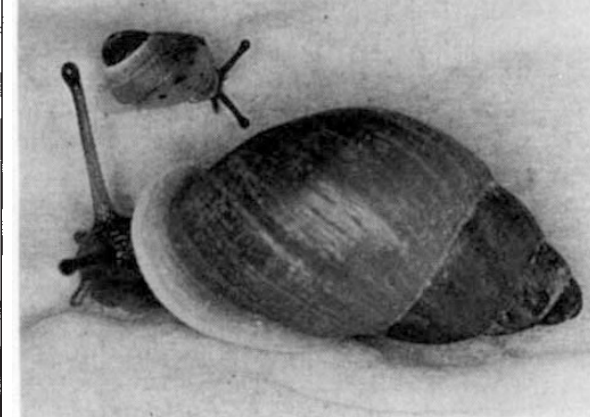

It's a snail-eat-snail world.

the island" and will probably die off. Then, the researchers hope, they can safely reintroduce the once-thriving Partula tree snails that Euglandina drove to extinction on Moorea in 1987.

In the meantime, the French Antienne Museum, which already has a research station on the island, is considering setting up a fenced-in, one-acre compound in which to start a trial reintroduction of
Partula. Among the various barricades that are being discussed to keep out the marauding Euglandina are screens, copper sheets, and electric fences. A yearround caretaker would have to watch the ramparts for breaches.

The tale of how the snail predators came to dominate the island is virtually a case study in bad biology. Island farmers brought Giant African land snails to Moorea in the mid-1960s as a food source. But the snails soon escaped from their farms and began to devour local crops. In 1977, local authorities, hoping to control the land snails, imported Euglandina. The predatory gastropods found the half-inch Partula more enticing, however, wiping them out in a decade.

Partula now exists only in some 3,000 snails of six species in a few breeding colonies around the world. And even those are proving hard to maintain, as some colonies inexplicably 'crash' from hundreds of snails to just a few individuals. In their research on a small nearby island where some Partula still remain in the wild, expedition team members may have found an explanation. Dead leaves and high humidity turn out to be more important to Partula diet and environment than they had realized, they say. Eating their own faeces - or "reingesting their gut flora", as the biologists put it - also appears to be more important to Partula digestion than thought. "We may have been keeping their cages too clean," says team leader Dave Clarke of the London Zoo.
Christopher Anderson 